\title{
SYNTHESIS AND CHARACTERIZATION OF TITANIUM DIOXIDE NANOMATERIALS VIA HORIZONTAL VAPOR PHASE GROWTH (HVPG) TECHNIQUE
}

\author{
Leapheng Uon ${ }^{1, a}$, Gil Nonato Santos ${ }^{2, b}$, and Alvin Chua ${ }^{3, c}$ \\ ${ }^{1,3}$ Mechanical Engineering Department, De La Salle University, Manila, Philippines \\ ${ }^{2}$ Physics Department, De La Salle University, Manila, Philippines, e-mail: aleapheng_uon@dlsu.edu.ph, \\ bgil.santos@dlsu.edu.ph, ${ }^{\mathrm{c}}$ alvin.chua@dlsu.edu.ph
}

Received Date: September 13, 2019; Revised Date: December 14, 2019 ; Acceptance Date: March 9, 2020

\begin{abstract}
This study aims to synthesize and characterize titanium dioxide nanomaterials via horizontal vapor phase growth (HVPG) technique toward making a sensor for detecting engine oil degradation. The growth temperature was varied at $1000^{\circ} \mathrm{C}, 1100^{\circ} \mathrm{C}$, and $1200^{\circ} \mathrm{C}$ with the fixed baking time of $6 \mathrm{hrs}$ and ramp rate of $10^{\circ} \mathrm{C} / \mathrm{min}$. The said nanomaterials grown on glass substrate were characterized by scanning electron microscope (SEM) and energy dispersive x-ray (EDX) to analyze the surface structure morphology and determine the elemental composition, respectively. Results showed that various sizes of titanium dioxide particles were found on the substrate surface at the proposed growth mechanisms.
\end{abstract}

Keywords: Horizontal vapor phase growth technique, Nanomaterials, Titanium dioxide

\section{Introduction}

Titanium dioxide $\left(\mathrm{TiO}_{2}\right)$ nanomaterials, one of the well-known metal oxides, have gained research interest and used in wide range of applications especially in gas sensor, batteries, air purification, and solar cell applications because of its wide band gap, high refractive index, high physical and chemical stability, electronic and optical properties, low cost, and non-toxicity [1,2]. Recently, it has been utilized for fabricating the sensor applied in engine oil degradation monitoring because of its high sensitivity, chemical stability, and electrical properties of the nanomaterials used. In the study of [3], $\mathrm{TiO}_{2}$ nanolayers pasted on glass substrate were proposed for acidic sensing of the used and fresh engine oil. In addition, the work conducted by [4], imprinting the $\mathrm{TiO}_{2}$ nanoparticles on quartz crystal microbalance (QCM) was employed successfully for capric acid detection with the aim of determining the engine oil's quality. Moreover, in the work of [5], $\mathrm{TiO}_{2}$ layers were selected as a favorable material for interacting with acidic products generated by engine oil oxidation. The study done by [6], $\mathrm{TiO}_{2}$ layers coated on shear transverse wave (STW) resonators were used as receptors for detecting oxidized products produced from the engine lubricant degradation.

There are several methods of fabricating the $\mathrm{TiO}_{2}$ nanomaterials that were used in previous studies such as sol-gel [1,3-7], chemical vapor deposition [8,9], and physical vapor deposition. However, the said methods are still inefficient strategies to synthesize the $\mathrm{TiO}_{2}$ nanomaterials for an engine oil sensor. The disadvantages of the existing methods are the following: the slow process of fabrication and costly implementation. Other disadvantages are the difficulty in controlling the surface morphology and the complex methodology of the material synthesis. Some of the methods also produce problems on chemical disposal and human health hazards. Therefore, the horizontal vapor phase growth (HVPG) technique was 
recently introduced to synthesize the different kinds of nanomaterials because of the benefits such as an economical and reliable method and less source material with high purity and the larger quantity of the nanomaterials generated. Distinct metal oxide nanomaterials were successfully fabricated through the said technique for sensor applications. For instance, iron oxide nanoparticles and zinc oxide nanomaterials and different nanostructures of tin oxide were fabricated successfully via HVPG for glucose detection [10] and gas sensing application $[11,12,13]$, respectively. Moreover, this said technique was also used to produce the distinct nanocomposites for coating application including silver-titanium dioxide $[14,15,16,17]$ and silver-graphene[18]. Hence, HVPG technique is proposed in this study to synthesize the titanium oxide $\left(\mathrm{TiO}_{2}\right)$ nanomaterials for engine oil applications instead of the previous techniques.

\section{Theory}

As presented in Figure 1, the HVPG technique, a top-down synthesized method, is categorized as spontaneous growth using evaporation-condensation process at a very low pressure around $10^{-6}$ Torr [19]. It has three basic principles including the vaporization of the material, transportation of the vapor, and condensation [19,20,21]. First, the source material in the formation of powder is vaporized in the shape of atomic species or molecular species heated by high-temperature source i.e. furnace. Second, this vaporized material is then transported to the substrate surface and lastly it is condensed and deposited on the substrate surface because of the temperature differences along the tube from the hottest zone to the coolest zone to produce the distinct kind of nanomaterials.

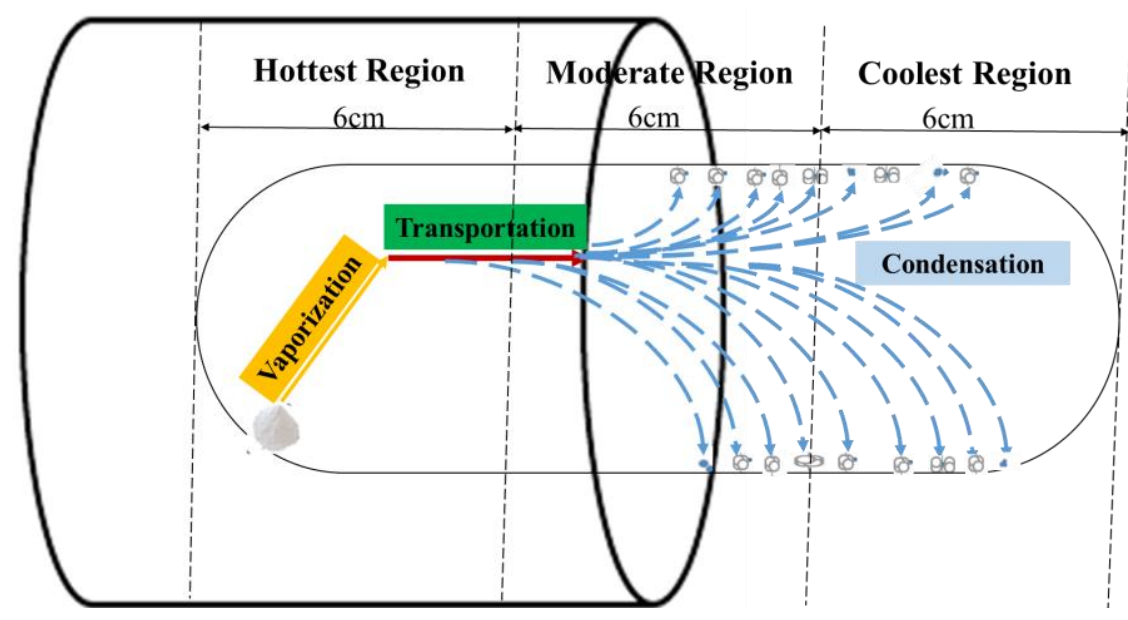

Figure 1. HVPG technique

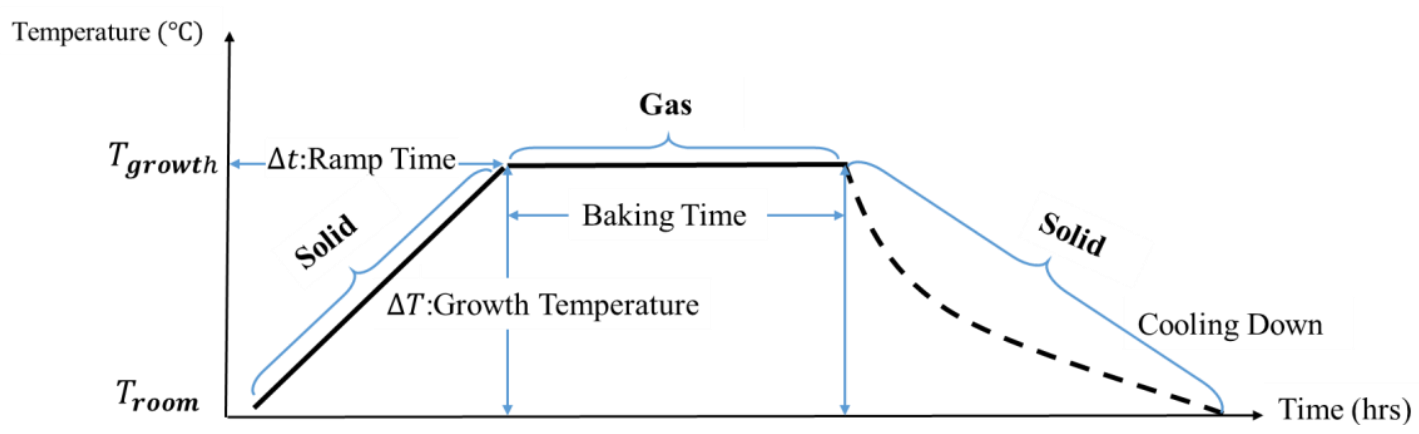

Figure 2. HVPG growth temperature profile 
As seen in Figure 2, the relationship between the phase transition of the source powder and temperature changes is presented in the growth temperature profile. It has two phase changes including sublimation and deposition. In the first transition, the source powder in the form of solid is changed into vapor once the temperature is increased up to the ultimate point. The deposition is then taken place by transforming the vapor to solid for generating the nanomaterials grown on the glass substrate when decreasing the temperature.

\section{Methodology}

The quart tube with dimensions of an inner diameter of $10 \mathrm{~mm}$, an outer diameter of $12 \mathrm{~mm}$, and a length of $300 \mathrm{~mm}$ substrate was prepared and then sealed fully its one end as seen in Figure 3(a). It was then cleaned using an ultrasonic cleaner in the duration of 30 minutes and allowed to dry in the air as presented in Figure 3(b). A $35 \mathrm{mg}$ of $\mathrm{TiO}_{2}$ (anatase) powder was weighed and loaded into the cleaned tube as shown in Figure 3(c). After which, it was then connected to the thermionics high vacuum system for the purpose of lowering the pressure to approximately $10^{-6}$ Torr as revealed in Figure 3(d). After reaching the desired pressure, the tube was sealed fully and detached using a mixture of oxygen and LPG blowtorch. For the sake of nanomaterials fabrication, the closed-end tube was placed halfway inside the thermolyne horizontal tube furnace to create the temperature gradients along the tube between the hottest zone and coolest zone as seen in Figure 3(e). That condition induced various types of nanomaterials to grow optimally at the divided zones. In this study, the furnace was set at the fixed baking time of $6 \mathrm{hrs}$ and ramp rate of $10^{\circ} \mathrm{C} / \mathrm{min}$ and the varied temperature of $1000^{\circ} \mathrm{C}, 1100^{\circ} \mathrm{C}$, and $1200{ }^{\circ} \mathrm{C}$. After finishing baking, the tube was allowed to cool down until reaching the room temperature. And then, the baked tube was brought out from the furnace and divided into three zones namely A (hottest zone), B (moderate zone) and $\mathrm{C}$ (coolest zone) and then cracked slowly to obtain the glass substrate containing a different kind of nanomaterials using for characterization purposes. Scanning electron microscope (SEM) and energy dispersive $x$-ray (EDX) were utilized for analyzing surface morphology and topology and determining the chemical composition, respectively.
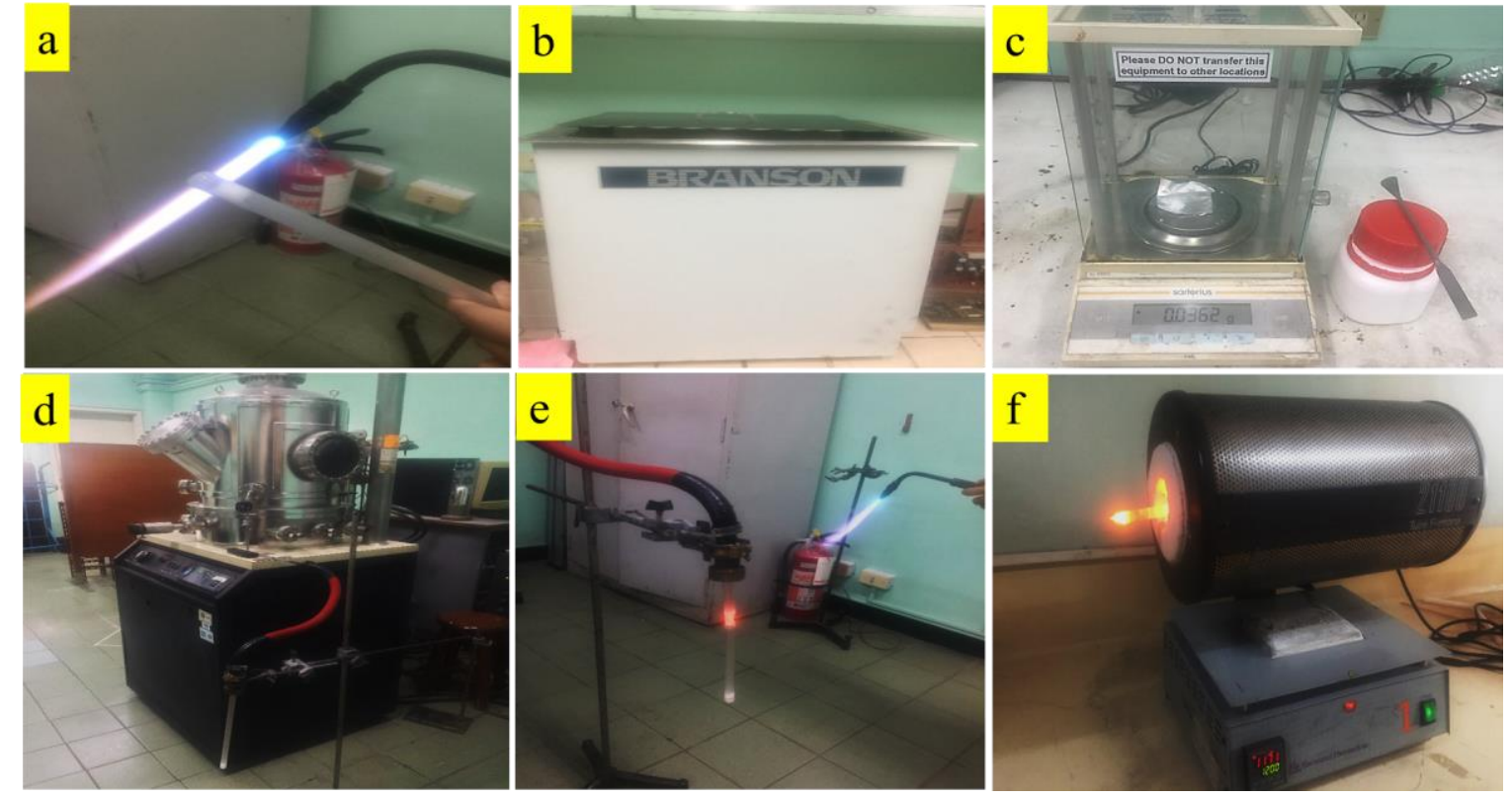

Figure 3. (a) Sealing one end of the tube (b) cleaning the tube using ultrasonic cleaner (c) weighing the $\mathrm{TiO}_{2}$ powder (d) lowering the pressure inside the tube to about $10^{-6}$ Torr and sealing its other end after reaching the desired pressure, and (e) placing the tube haft way inside the furnace 


\section{Results and Discussion}

Scanning electron microscope (SEM) and energy dispersive $\mathrm{x}$-ray (EDX) were used as a tool to characterize the surface structure morphology and the elemental composition of the grown nanomaterials, respectively. Nanomaterial characterization was needed to study the structure of the grown nanomaterials for the purpose of selecting the appropriate nanomaterials such as nanoparticles for fabricating the engine oil sensor. The selected surface structure was very important for sensor fabrication since it affects sensor performance.

\section{Scanning Electron Microscope (SEM) Results}

Based on SEM results, various sizes of the $\mathrm{TiO}_{2}$ particles were grown on the glass substrate in zone $\mathrm{B}$ and zone $\mathrm{C}$ at the varied growth temperature and baking time as seen in Figure 49. These results presented a similar type of $\mathrm{TiO}_{2}$ particles with the previous study on the synthesis of titanium dioxide nanomaterials via sol-gel methods [22]. In the case of the same type and formation of particles generated, it can be noted that particle size, aggregation, and agglomeration were changed in terms of varying the growth mechanisms and selecting zones. As shown at $1000^{\circ} \mathrm{C}$ and $6 \mathrm{hrs}$ for both zone B and C, the particle sizes were decreased when raising the growth temperature up to $1100^{\circ} \mathrm{C}$ and $1200^{\circ} \mathrm{C}$. Moreover, there were more agglomeration and aggregation of the particles once the controlled temperature was increased. Unlike, it was less agglomerated and aggregated when the low temperature was selected. Furthermore, the shape of grown particles was changed to spherical forms in the matter of decreasing the growth temperature. As presented in Table 1 and Table 2, the measured diameters of the grown $\mathrm{TiO}_{2}$ particles are listed for zone $\mathrm{B}$ and zone $\mathrm{C}$, respectively. For the purpose of fabricating the engine oil sensor, the grown $\mathrm{TiO}_{2}$ particles were selected because of its high sensitivity of acidity detection based on literature $[3,4,5,6]$.

\section{Zone B}

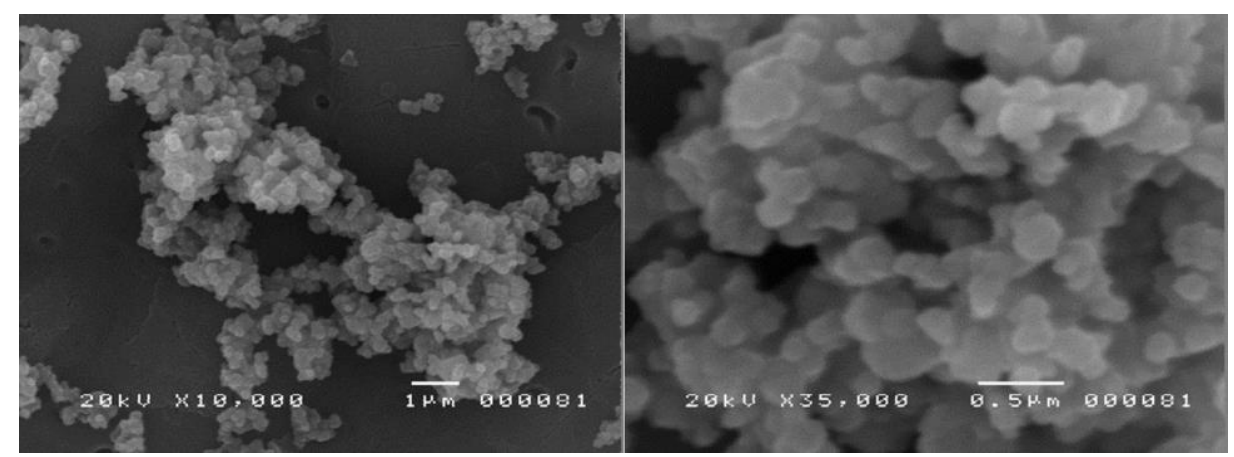

Figure 4. $\mathrm{TiO}_{2}$ particles generated at $1200{ }^{\circ} \mathrm{C}$ and $6 \mathrm{hrs}$

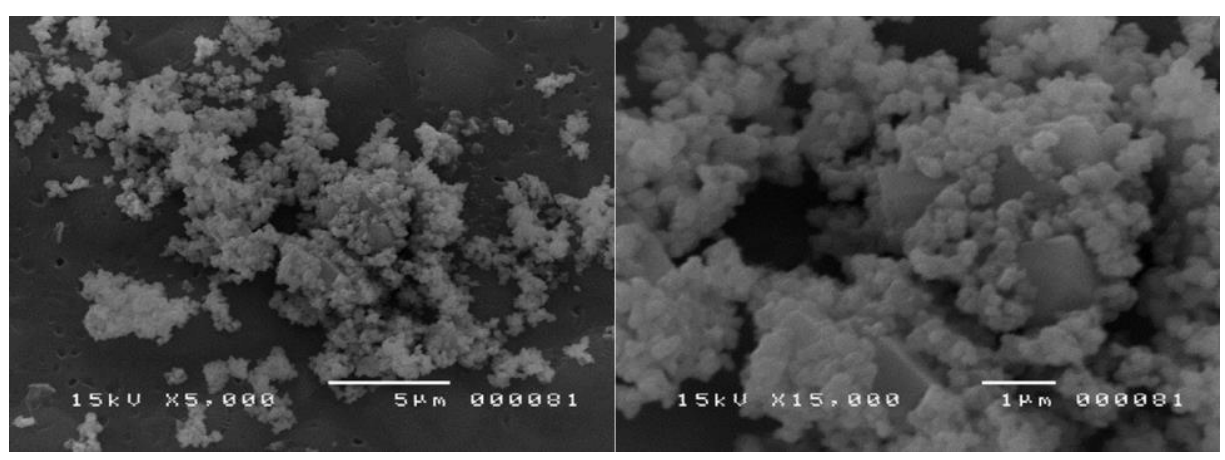

Figure 5. $\mathrm{TiO}_{2}$ particles generated at $1100{ }^{\circ} \mathrm{C}$ and $6 \mathrm{hrs}$ 


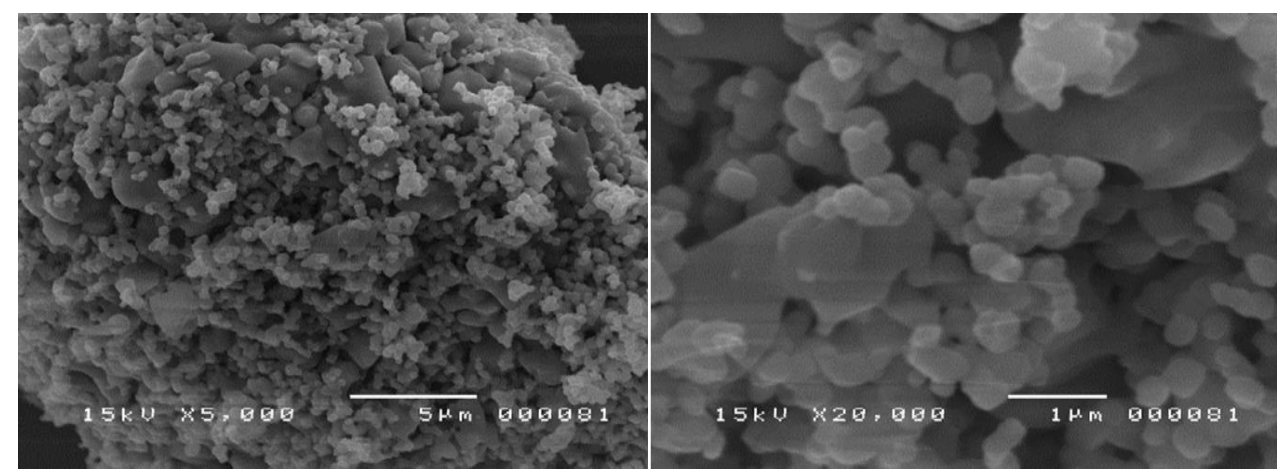

Figure 6. $\mathrm{TiO}_{2}$ particles generated at $1000^{\circ} \mathrm{C}$ and $6 \mathrm{hrs}$

\section{Zone $C$}

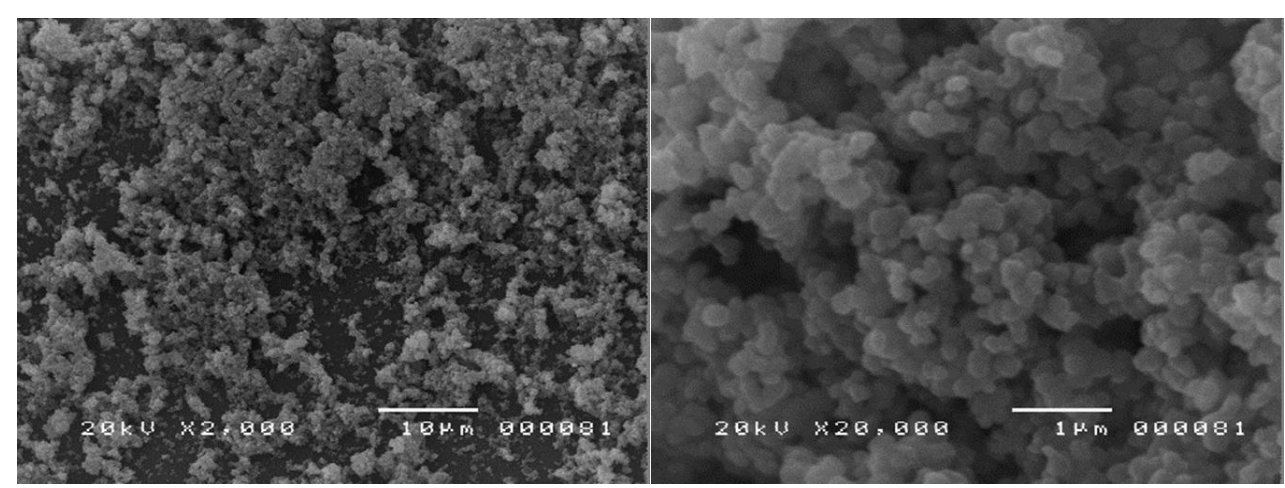

Figure 7. $\mathrm{TiO}_{2}$ particles generated at $1200^{\circ} \mathrm{C}$ and $6 \mathrm{hrs}$

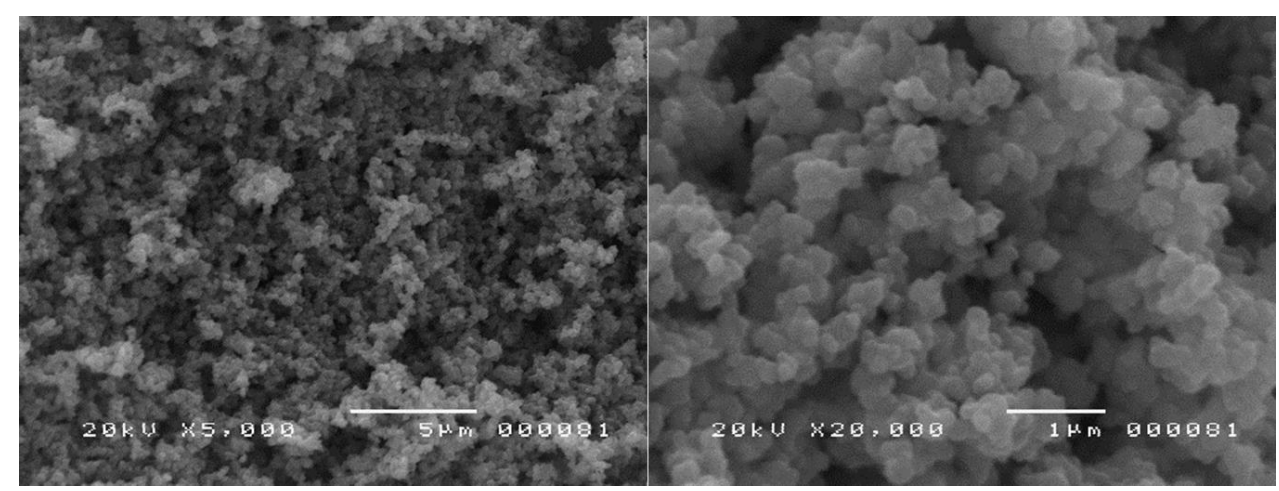

Figure $8 . \mathrm{TiO}_{2}$ particles generated at $1100^{\circ} \mathrm{C}$ and $6 \mathrm{hrs}$

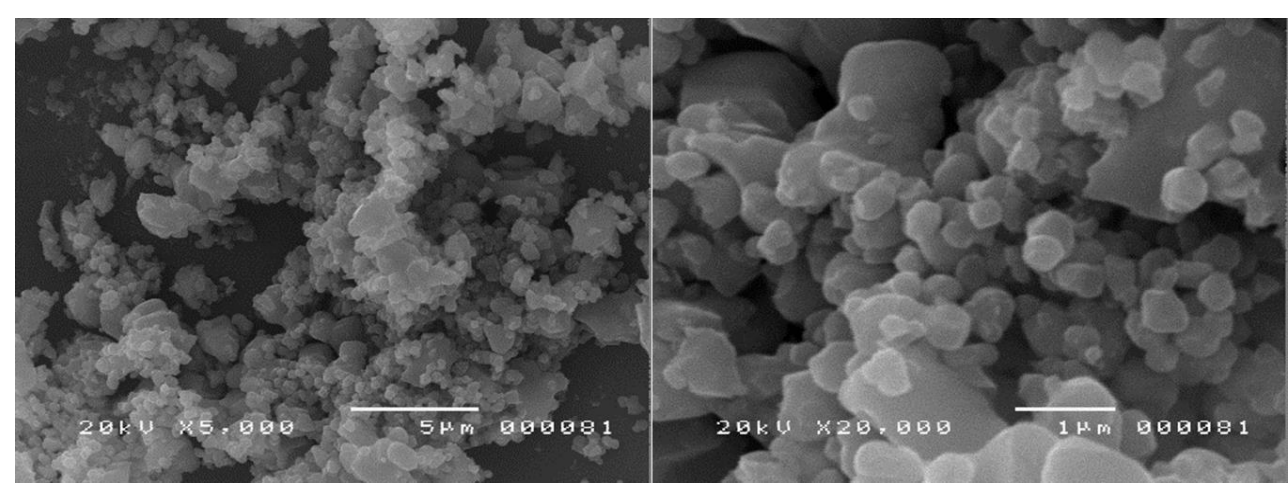

Figure 9. $\mathrm{TiO}_{2}$ particles generated at $1000^{\circ} \mathrm{C}$ and $6 \mathrm{hrs}$ 
Table 1. Diameter Measurement of the $\mathrm{TiO}_{2}$ Particle in Zone $\mathrm{B}$

\begin{tabular}{ccc} 
Growth Temperature $\left({ }^{\circ} \mathbf{C}\right)$ & Baking Time (hrs) & Diameter Range (nm) \\
\hline 1200 & 6 & $80-160$
\end{tabular}

$\begin{array}{lll}1100 & 6 & 91-168 \\ 1000 & 6 & 135-260\end{array}$

Table 2. Diameter Measurement of the $\mathrm{TiO}_{2}$ Particle in Zone $\mathrm{C}$

Growth Temperature $\left({ }^{\circ} \mathrm{C}\right) \quad$ Baking Time (hrs) Diameter Range (nm)

$\begin{array}{lll}1200 & 6 & 113-173 \\ 1100 & 6 & 115-206 \\ 1000 & 6 & 189-319\end{array}$

\section{Energy Dispersive X-ray (EDX) Results}

All of the grown particles at the varied growth temperature and fixed baking time were proceeded with EDX analysis to determine the elemental composition. As shown in Figure 10, Figure 11, and Figure 12, results revealed the atomic percentage of titanium and oxygen of the grown particles. It can be concluded that all of them had the right atomic ratio of titanium to oxygen which is around 1:2.

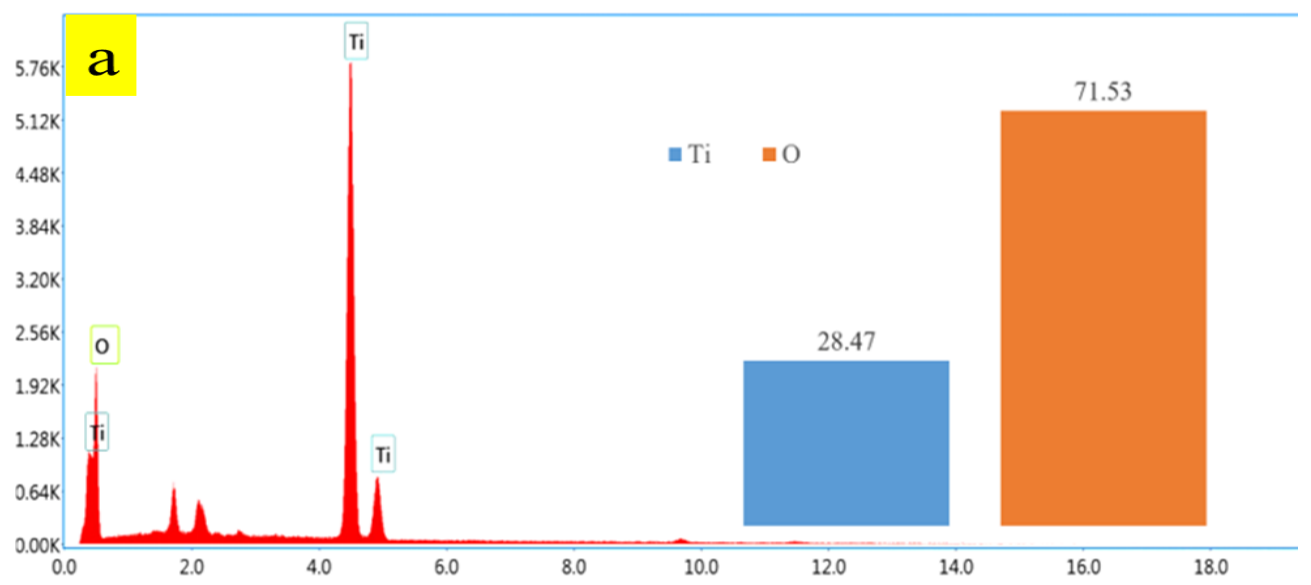

Figure 10. EDX spectrum of $\mathrm{TiO}_{2}$ particles at $1000^{\circ} \mathrm{C}$

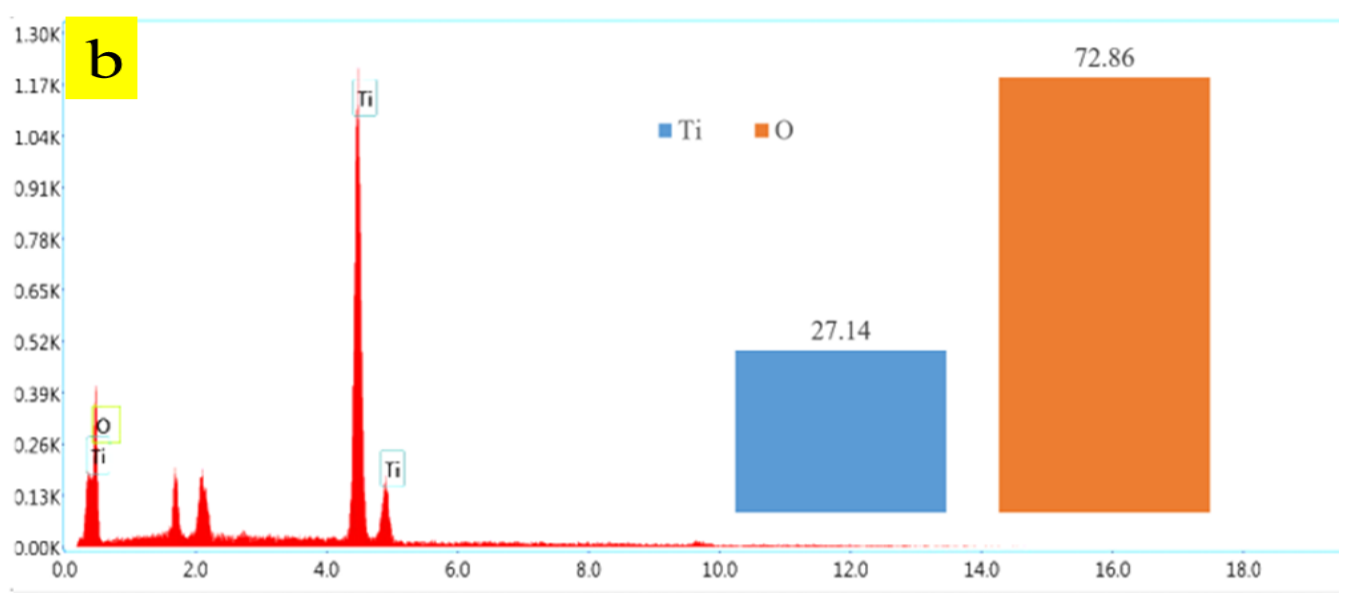

Figure 11. EDX spectrum of $\mathrm{TiO}_{2}$ particles at $1100^{\circ} \mathrm{C}$ 


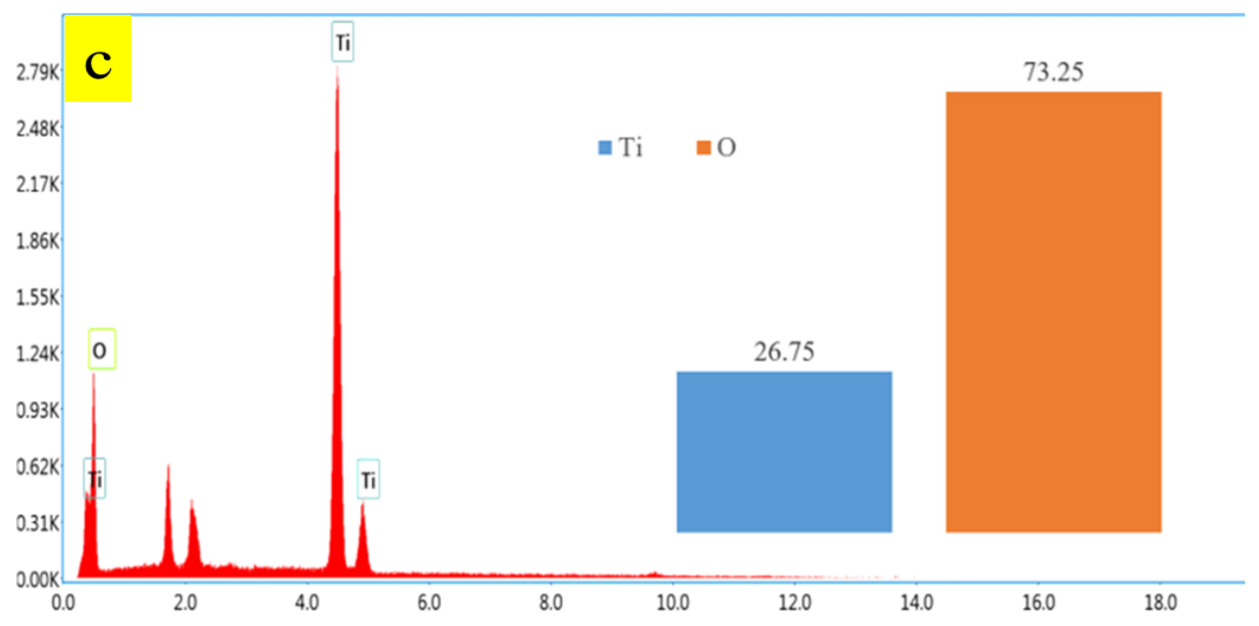

Figure 12. EDX spectrum of $\mathrm{TiO}_{2}$ particles at $1200^{\circ} \mathrm{C}$

\section{Conclusions}

Results proved that different forms and sizes of the titanium dioxide particles were synthesized successfully using HVPG at the various growth temperature of $1000^{\circ} \mathrm{C}, 1100^{\circ} \mathrm{C}$, and $1200{ }^{\circ} \mathrm{C}$ with the fixed baking time of $6 \mathrm{hrs}$ and ramp rate of $10^{\circ} \mathrm{C} / \mathrm{min}$ for fabricating the sensor device. Based on SEM results, it can be noted that the particle size, aggregation, and agglomeration were changed in terms of varying the growth temperature. For the further synthesis of $\mathrm{TiO}_{2}$ nanomaterials via HVPG, researchers should focus on increasing the growth temperature up its melting point to enhance the understanding of the changes in the amount of the grown particles due to its higher melting point.

\section{Acknowledgments}

The authors would like to express gratitude to AUN/Seed-Net Scholarship for providing financial support for this research and also Solid State Physic Lab for facilitating the experiment.

\section{References}

[1] S. Bagheri, K. Shameli, and S.B.A. Hamid, "Synthesis and characterization of anatase titanium dioxide nanoparticles using egg white solution via sol-gel method," Journal of Chemistry, Vol. 2013, pp. 1-5, 2013.

[2] N. Rahaf, K. Kamal, and A. Hammoud, "Spectroscopic study of titanium dioxide thin films prepared by pulsed laser deposition," Journal of Nanoelectronics and Optoelectronics, Vol. 9, No. 2, pp. 251-256, 2019.

[3] U. Latif, and F.L. Dickert, "Conductometric sensors for monitoring degradation of automotive engine oil," Sensors, Vol. 11, No. 9, pp. 8611-8625, 2011.

[4] P.A. Lieberzeit, A. Afzal, G. Glanzing, and F.L. Dickert, "Molecularly imprinted sol-gel nanoparticles for mass-sensitive engine oil degradation sensing," Analytical and Bioanalytical Chemistry, Vol. 389, No. 2, pp. 441-446, 2007.

[5] A. Mujahid, P.A. Lieberzeit, and F.L. Dickert, "Chemical sensors based on molecularly imprinted sol-gel materials," Materials (Basel), Vol. 3, No. 4, pp. 2196-2217, 2010.

[6] A. Mujahid, A. Afzal, G. Glanzing, A. Leidl, P.A. Lieberzeit, and F.L. Dickert, "Imprinted sol-gel materials for monitoring degradation products in automotive oils by shear transverse wave," Analytica Chimica Acta, Vol. 675, No. 1, pp. 53-57, 2010. 
[7] R. Devi, R. Venckatesh, and R. Sivaraj, "Synthesis of titanium dioxide nanoparticles by sol-gel technique," International Journal of Innovative Research in Science, Engineering and Technology, Vol. 3, No. 8, pp. 15206-15211, 2014.

[8] Q. Zhang, and C. Li, "Pure anatase phase titanium dioxide films prepared by mist chemical vapor deposition," Nanomaterials, Vol. 8, No. 10, p. 827, 2018.

[9] H. Liu, Y. Zhang, R. Li, M. Cai, and X. Sun, "A facile route to synthesize titanium oxide nanowires via water-assisted chemical vapor deposition," Journal of Nanoparticle Research, Vol. 13, No. 1, pp. 385-391, 2010.

[10] D.M.B. De Mesa, G.N.C. Santos, and R.V Quiroga, "Synthesis and characterization of $\mathrm{Fe}_{2} \mathrm{O}_{3}$ nanomaterials using hvpg growth technique for glucose sensing application," International Journal of Scientific and Engineering Research, Vol. 3, No. 8, pp. 1-12, 2012.

[11] F.C. Bancolo, G.N.C. Santos, and R.V Quiroga, "Fabrication and characterization of $\mathrm{SnO}_{2}$ nanomaterial as $\mathrm{CO}_{2}$ gas sensor," International Journal of Scientific and Engineering Research, Vol. 3, No. 8, pp. 1-6, 2012.

[12] J.C. Briones, G. Castillon, M.P. Delmo, and G.N.C. Santos, "Magnetic-field-enhanced morphology of tin oxide nanomaterials for gas sensing applications," Journal of Nanomaterials, Vol. 2017, 2017.

[13] K.J.F. Haygood, "Fabrication and characterization of zinc oxide nanomaterials for gas sensing application," Thesis (Master's), De La Salle University, Manila, Philippines, 2016.

[14] M.A. Muflikhun, G.N. Santos, and A.Y. Chua, "Synthesis and characterization of silver-titanium nanocomposite via horizontal vapor phase growth (hvpg) technique," DLSU Research Congress, Vol. 3, pp. 2-6, 2015.

[15] M.A. Muflikhun, M.C. Frommelt, M. Farman, A.Y. Chua, and G.N.C. Santos, "Structures, mechanical properties and antibacterial activity of $\mathrm{Ag} / \mathrm{TiO}_{2}$ nanocomposite materials synthesized via hvpg technique for coating application," Heliyon, Vol. 5, No. 4, 2019

[16] M.A. Muflikhun, A.Y. Chua, and G.N.C. Santos, "Structures, morphological control, and antibacterial performance of $\mathrm{Ag} / \mathrm{TiO}{ }_{2}$ micro-nanocomposite materials," Advances in Materials Science and Engineering, Vol. 2019, pp. 1-12, 2019.

[17] M.A. Muflikhun, A.Y. Chua, and G.N.C. Santos, "Statistical design analysis of silvertitanium dioxide nanocomposite materials synthesized via horizontal vapor phase growth (HVPG)," Key Engineering Materials, Vol. 735, pp. 210-214, 2017.

[18] M.A. Muflikhun, G.B. Castillon, G.N.C. Santos, and A.Y. Chua, "Micro and nano silver-graphene composite manufacturing via horizontal vapor phase growth (hvpg) technique," In: I. Kartini, Roto, D. Siswanta, and K. Triyana, eds., Materials Science Forum, Scientific.Net, Switzerland, Vol. 901, pp. 3-7, 2017.

[19] G.N.C. Santos, A.A. Salvador, and R.V Quiroga, Horizontal vapor phase growth (hvpg). Intellectual Property Office of the Philippines 1-2009-000146, 2011

[20] "Physical vapor deposition technique for growing nanostructures," Available: http://www.nanoscience.gatech.edu/zlwang/research/pvd.html. [Accessed: October 2018].

[21] A. Ole, P.M.B. Abrasaldo, G. Castillon, A. Ladines, R. de los Reyes, G.N.C. Santos, and R.V. Quiroga, "Synthesis of $\mathrm{TiO}_{2}$ nanomaterials by modified horizontal vapor phase growth technique," pp. 1-4.

[22] S.T. Hayle, and G.G. Gonfa, "Synthesis and characterization of titanium oxide nanomaterials using sol-gel method," American Journal of Nanoscience and Nanotechnology, Vol. 2, No. 1, p. 1, 2014. 